\title{
О ВОЗМОЖНОСТИ ПРОГНОЗИРОВАНИЯ СОДЕРЖАНИЯ ТРИГАЛОГЕНМЕТАНОВ В ПИТЬЕВОЙ ВОДЕ ПОВЕРХНОСТНЫХ И ИНФИЛЬТРАЦИОННЫХ ВОДОЗАБОРОВ С ПОМОЩЬЮ УРАВНЕНИЙ МНОЖЕСТВЕННОЙ ЛИНЕЙНОЙ РЕГРЕССИИ*
}

\author{
Малкова Мария Александровна, Кантор Евгений Абрамович
}

Уфимский государственный нефтяной технический университет, 450064, Россия, Республика Башкортостан, г. Уфа, ул. Космонавтов, 1

Малкова М.A., email: kykyshka2009@mail.ru Кантор E.A., email: evgkantor@mail.ru

Обеспечение населения качественной питьевой водой является первостепенной задачей, поскольку ежегодно возрастающее химическое и биологическое загрязнение способствует снижению качества воды водоисточника. Низкое качество воды водоисточника осложняет производство питьевой воды, отвечающей современным критериям физиологической полноценности, безвредности по химическому и бактериологическому составу [7-12]. Кроме того, многочисленными исследованиями доказано, что присутствие в питьевой воде органических токсикантов приводит к увеличению количества соматических, неврологических и онкологических заболеваний человека. Качество воды водоисточника характеризуется значительными сезонными колебаниями. Изменение свойств воды оказывает влияние на работу коммунальных водоочистных сооружений [19,20,23].

Среди существующих методов обеззараживания воды хлорирование получило повсеместное применение. Для обеззараживания воды хлорированием применяют молекулярный хлор и активные хлорсодержащие соединения. Однако такой способ приводит к образованию продуктов хлорирования - галогенорганических соединений, - большая часть которых приходится на тригалогенметаны (ТГM): хлороформ $\mathrm{CHCl}_{3}$ (ТХM), 
бромдихлорметан $\mathrm{CHBrCl}_{2}$ (БДХМ), дибромхлорметан $\mathrm{CHBr}_{2} \mathrm{Cl}$ (ДБХМ) и бромоформ $\mathrm{CHBr}_{3}$ (ТБМ) $[1,2-5,10,14]$.

Предшественниками образования хлорированных продуктов являются гуминовые вещества и фитопланктон [6]. Определенная роль в процессе галоидирования принадлежит неорганическим бромидам, которые могут являться как естественными примесями природных вод, так и быть продуктами разложения бромсодержащих пестицидов, противонагарных присадок, противоинеевых агентов и т.д. [2,13,16].

Нами проведено сравнение качества питьевой воды по содержанию ТГМ поверхностного водозабора ковшового типа и инфильтрационного водозабора, которые используют воду одного водоисточника. Створ поверхностного водозабора расположен в промышленной зоне выше по течения реки, а на створ инфильтрационного водозабора, расположенного ниже по течению реки, оказывают влияние городская агломерация, включающая промышленную и зону компактного проживания населения [11].

Результаты многолетних наблюдений за содержанием ТГМ в водоисточнике показывают, что броморганические соединения значительно уступают по содержанию ТХМ. Стоит отметить, что, зачастую ДБХМ, БДХМ и ТБМ отсутствуют в природной воде или содержатся в концентрациях ниже предела обнаружения. Начиная с 2000 года, ТБМ в составе речной воды не обнаруживался, ТХМ практически всегда присутствует в речной воде, являясь ее «фоновым» загрязнителем.

В створе ПВ концентрация ТХМ несколько ниже, чем в створе ИВ (рис.1). Возможно, что на створ ИВ помимо промышленной, значительное влияние оказывает и городская зона [18].

Очистные сооружения на ПВ включают станцию ультрафиолетового обеззараживания, микрофильтры, горизонтальные отстойники и скорые фильтры. Вода подвергается двойному хлорированию (сразу после забора воды и перед ее подачей в распределительную сеть города). Отсутствие данных по образования ТГМ после введения первичной дозы хлора 
предопределяет использование в расчетах суммарной дозы хлора. Очистка воды на инфильтрационном водозаборе состоит из естественной фильтрации воды и стадии обеззараживания.
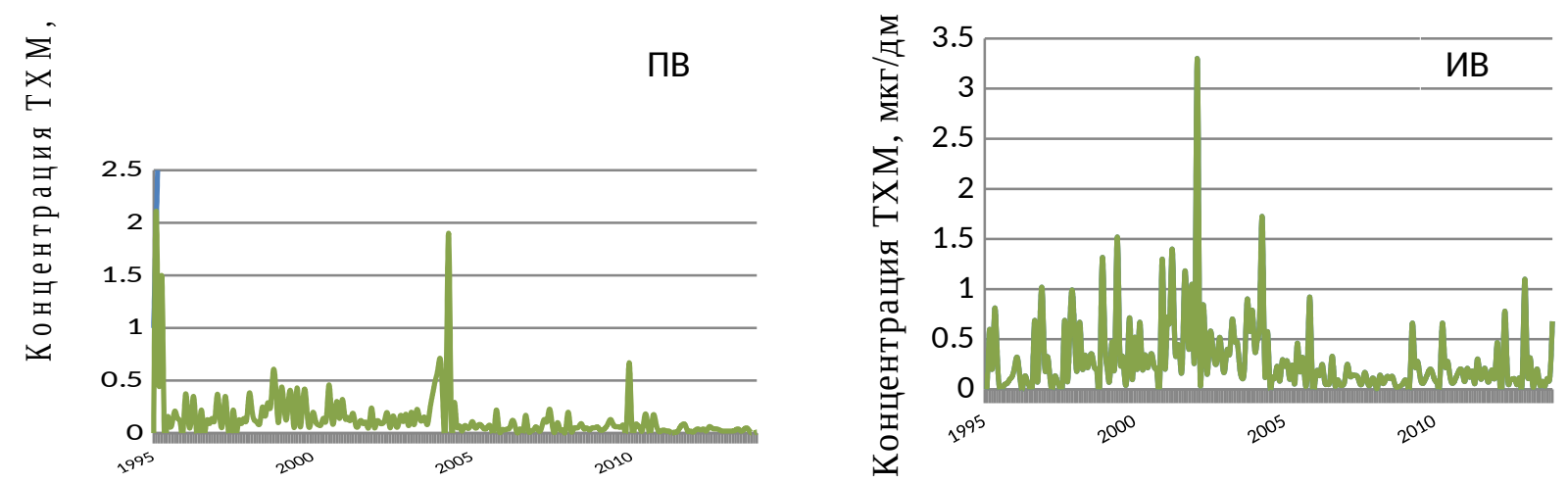

Рисунок 1 - Временные ряды содержание ТХМ в створах водоисточника (реки) поверхностного (ПВ) и инфильтрационного водозаборов (ИВ)

Более загрязненной по ТГМ является питьевая вода поверхностного водозабора (рис.2). Несмотря на однократные превышения значений истинных концентраций по сравнению с предельно-допустимыми, среднемноголетние значения компонентов ТГМ в резервуаре чистой воды (РЧВ) в подавляющем большинстве случаев существенно ниже ПДК (рис. 2).

Анализ опубликованных данных показывает, что факторами, влияющими на процесс образования ТГМ, являются доза хлорсодержащего дезинфектора, количество гумуса в речной воде, время контакта воды с хлорсодержащими агентами, pH, температура и др. [4,17].

Аналитический контроль качества воды на сооружениях водоподготовки включает такие параметры, как мутность, цветность, окисляемость, и не предусматривает прямого определения предшественников ТГМ. В этой связи представляется обоснованным рассмотреть взаимосвязь между количеством образовавшихся ТГМ, дозой хлора (Дсі) и обобщенными 
показателями качества воды (мутность (M), цветность (Ц), окисляемость (O)) $[21,22]$.
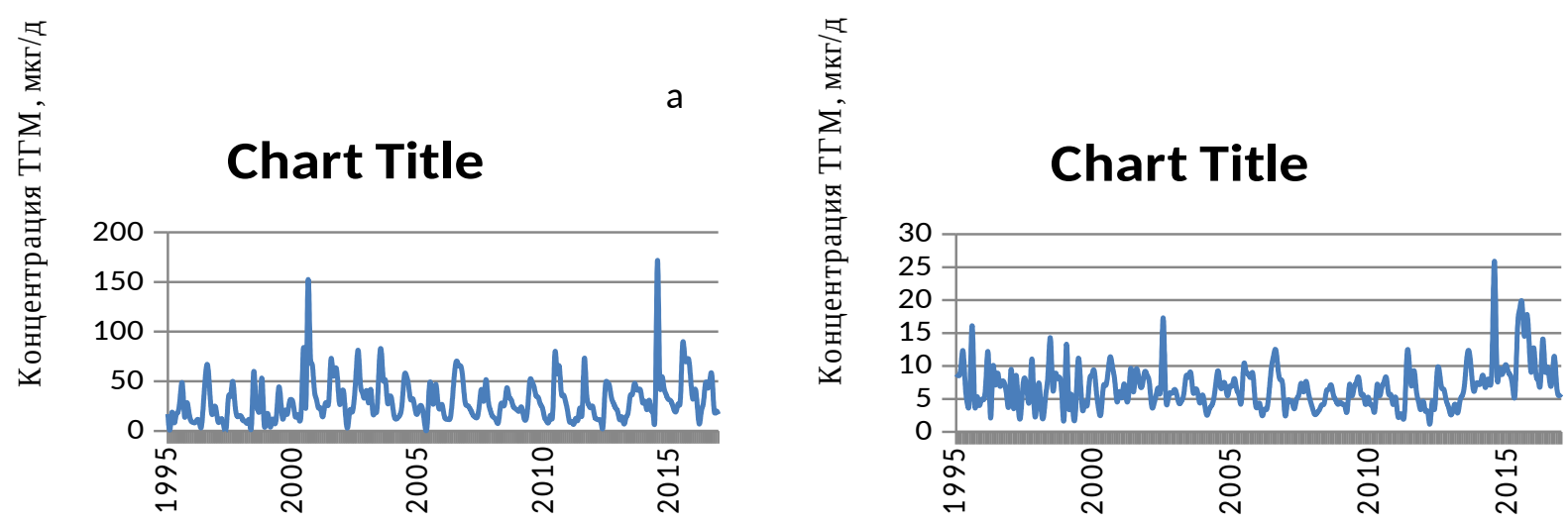

Год

Год

Рисунок 2 - Временные ряды суммарного содержания ТГМ в РЧВ водозаборов ПВ (а) и ИВ (б) (1995 - 2016 гг.)

Расчет коэффициентов корреляции выявил умеренную силу связи (по шкале Чеддока) между концентрацией ТГМ и дозой хлора в питьевой воде ПВ (табл.1). Для ИВ эта связь характеризуется как слабая. Между концентрацией ТГМ и мутностью, цветностью и окисляемостью связь определяется как слабая (табл.1).

Таблица 1 - Результаты расчета парных коэффициентов корреляции между ТГМ и Ц, О на ПВ и ИВ

\begin{tabular}{|c|c|c|c|c|}
\hline & $Д_{\mathrm{Cl}}$ & $M$ & Ц & $\mathrm{O}$ \\
\hline \multicolumn{5}{|c|}{ ПВ } \\
\hline ТГМ & 0,45 & $-0,22$ & 0,09 & 0,22 \\
\hline \multicolumn{5}{|c|}{ ИВ } \\
\hline ТГМ & 0,22 & $-0,09$ & 0,01 & 0,13 \\
\hline
\end{tabular}

Получено уравнение множественной регрессии (зависимость суммарной концентрации ТГМ на водозаборах ПВ (1) и ИВ (2) от дозы хлорирующего агента, мутности, цветности и окисляемости) (1).

$$
\begin{aligned}
& \text { ТГМ = 7,85 + 11,82 Д } \text { Сl }-1,03 \mathrm{M}-0,35 Ц+5,98 \mathrm{O} \\
& \mathrm{R}^{2}=0,30 ; \mathrm{S}=18,7 ; \mathrm{F}=20,8 ; \mathrm{A}=51,0 \% \\
& \mathrm{T \Gamma M}=-0,68+10,46 Д_{\mathrm{Cl}}-0,11 \mathrm{M}+0,85 \mathrm{O}
\end{aligned}
$$




$$
\mathrm{R}^{2}=0,08 ; \mathrm{S}=5,7 ; \mathrm{F}=6,3 ; \mathrm{A}=47,0 \%
$$

Доза хлора и окисляемость, согласно обоим уравнениям, увеличивают значение суммарной концентрации ТГМ, в то время как мутность и цветность на ПВ его снижает. Для ИВ цветность является незначимым фактором. Установлена статистическая значимость коэффициента детерминации и статистическая надежность уравнений регрессии для обоих типов водозаборов по критерию Фишера $[15,24]$. Однако, невысокие значения коэффициента детерминации регрессионного уравнения $\left(\mathrm{R}^{2}\right.$ равен 0,30 и 0,08 для ПВ и ИВ соответственно) можно считать свидетельством в пользу неудовлетворительного описания изменения суммарной концентрации ТГМ в зависимости от использованных параметров. Средняя ошибка аппроксимации полученных регрессионных уравнений составляет 47- 51 \% (табл. 2) [18].

Проведение аналогичных расчетов, использующих в качестве исходных данные указанных показателей, рассчитанные как средние за каждый из месяцев в году (сформированный годовой цикл), позволяет выявить высокие значения коэффициента детерминации 0,64 - 0,94 и низкие значения ошибок аппроксимации (10-13\%) (уравнения 3 (ПВ), 4(ИВ)).

$$
\begin{aligned}
& \text { ТГМ = -9,88 + 22,93 ДСl }-0,77 \text { M -2,59 Ц + 21,78 O } \\
& \mathrm{R}^{2}=0,94 ; \mathrm{S}=4,4 ; \mathrm{F}=33,4 ; \mathrm{A}=10,5 \% \\
& \text { ТГМ = 0,80 - 0,40 M + 2,89 O } \\
& \mathrm{R}^{2}=0,64 ; \mathrm{S}=1,8 ; \mathrm{F}=8,1 ; \mathrm{A}=13,4 \%
\end{aligned}
$$

Интересно отметить, что для описания содержания ТГМ в питьевой воде ПВ значимыми являются все факторы, в то время как для ИВ незначимыми оказались доза хлора и цветность. Оба уравнения имеют высокое значение коэффициента детерминации $(0,64$ и 0,94), низкую среднюю ошибку прогноза (10 и 13\%); критерий Фишера указывает на статистическую значимость полученных уравнений.

Необходимо отметить, что максимум суммарной концентрации ТГМ в 
сформированным годовом периоде приходится на июль как для ПВ, так и для ИВ. Для временных рядов окисляемости, цветности максимум значения приходится на май, мутности - на апрель (табл. 4). Таким образом, максимум концентрации ТГМ приходится на более поздний месяц в годовом цикле, остальные параметры опережают этот показатель на 1-3 месяца [18].

Таблица 4 - Изменение содержания ТГМ, дозы хлора, цветности, окисляемости, мутности в годовом цикле*

\begin{tabular}{|c|c|c|c|c|c|c|c|c|c|c|c|c|}
\hline $\begin{array}{l}\text { Месяц } \\
\text { Параметр }\end{array}$ & 1 & 2 & 3 & 4 & 5 & 6 & 7 & 8 & 9 & 10 & 11 & 12 \\
\hline \multicolumn{13}{|c|}{ ПВ } \\
\hline ТГМ & 3,7 & 11,5 & 11,4 & 11,7 & 11,8 & 31,3 & 1,8 & 51,3 & 38,5 & 31,3 & 27,5 & 23,3 \\
\hline Мутность, мг/д & 1,1 & 1,1 & 1,6 & 18,9 & 18,2 & 3,6 & 1,8 & 1,4 & 1,0 & 1,3 & 1,6 & 1,5 \\
\hline Цвет & 10,1 & 10,2 & & & 9,6 & 27,6 & 15,3 & 16,8 & 15,8 & 3,2 & 13,5 & 2,8 \\
\hline яемость, & 1,7 & 1,6 & 1,4 & 3,5 & 6,9 & 5,1 & 3,6 & 3,3 & 3,2 & 2,7 & 2,5 & 2,4 \\
\hline пора мг/ & 1,1 & 0,9 & 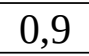 & 1,2 & 1,0 & 1,9 & 3 & 2, & 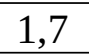 & 1,0 & 1,4 & 1,3 \\
\hline \multicolumn{13}{|c|}{ ИВ } \\
\hline ТГМ & 7,1 & 5,1 & 5,0 & 5,6 & 6,9 & 8, & 12,4 & 0, & 7, & 7,0 & 5,6 & 7,1 \\
\hline мг/дм ${ }^{3}$ & 1,0 & 1,0 & 1,2 & 24,7 & 19,4 & 3,8 & 2,1 & 2,2 & 1,3 & 1,8 & 1,4 & 2,1 \\
\hline,${ }^{0} Ц$ & 6,5 & 7,0 & 6,4 & 10,2 & 33,0 & 20,8 & 14,3 & 12 & 12,1 & 9,1 & 8,6 & 10,4 \\
\hline мость, & 1,9 & 1,7 & 1,6 & 4,3 & 7,1 & 4,3 & 3,9 & 3, & 3,1 & 2,8 & 2,5 & 2,5 \\
\hline Доза хлора, мг/дм ${ }^{3}$ & 0,53 & 0,52 & 0,51 & 0,53 & 0,56 & 0,58 & 0,63 & 0,62 & 0,61 & 0,58 & 0,57 & 0,56 \\
\hline
\end{tabular}

*жирным шрифтом выделены максимальные значения параметров

В результате обработки временных рядов, описывающий годовой цикл, с учетом смещения зависимых параметров получены более высокие значения парных коэффициентов корреляции (табл. 5).

Таблица 5 - Значения парных коэффициентов корреляции между суммарной концентрацией ТГМ и параметрами до и после смещения (годовой цикл)

\begin{tabular}{|c|c|c|c|c|}
\hline \multirow{2}{*}{ Параметр } & \multicolumn{2}{|c|}{$\begin{array}{c}\text { Количество месяцев } \\
\text { смещения }\end{array}$} & $\begin{array}{c}\text { Коэффициенты корреляции } \\
\text { после смещения }\end{array}$ \\
\cline { 2 - 5 } & ПВ & ИВ & ПВ & ИВ \\
\hline М & 3 & 3 & 0,73 & 0,80 \\
\hline Ц & 2 & 2 & 0,81 & 0,91 \\
\hline $\mathrm{O}$ & 2 & 2 & 0,88 & 0,90 \\
\hline$Д_{\mathrm{cl}}$ & 0 & 0 & 0,86 & 0,81 \\
\hline
\end{tabular}


C помощью корреляционно-регрессионного анализа параметров годового цикла найдено уравнение, параметры которого свидетельствуют о высоком значении коэффициента корреляции и детерминации (0,98 и 0,86 соответственно), а также его достоверности по критерию Фишера (уравнения 5, 6). Средняя относительная ошибка составляет 8,8 и 10,1\%.

$$
\begin{aligned}
& \mathrm{T \Gamma M}=-5,47+12,16 Д_{\mathrm{Cl}}+0,73 \mathrm{M}-2,71 Ц+17,74 \mathrm{O} \\
& \mathrm{R}^{2}=0,98 ; \mathrm{S}=2,7 ; \mathrm{F}=103,2 ; \mathrm{A}=10,1 \% \\
& \mathrm{T \Gamma M}=-0,66+9,49 Д_{\mathrm{Cl}}+0,15 \mathrm{M}-0,22 \text { Ц 1,39 O } \\
& \mathrm{R}^{2}=0,86 ; \mathrm{S}=0,9 ; \mathrm{F}=11,6 ; \mathrm{A}=8,8 \%
\end{aligned}
$$

Учет смещения временных рядов истинных концентраций содержания ТГМ и параметров качества воды позволяет получить как в парных, так и в множественных зависимостях более высокую степень связи по сравнению с определенными с помощью уравнений (1) и (2) (табл.7,8).

Таблица 7 - Значения коэффициентов корреляции между суммарной концентрацией ТГМ и параметрами до и после смещения (ряд истинных концентраций)

\begin{tabular}{|c|c|c|c|c|c|c|}
\hline \multirow{2}{*}{ Параметр } & \multicolumn{2}{|c|}{$\begin{array}{c}\text { Количество месяцев } \\
\text { смещения }\end{array}$} & \multicolumn{2}{c|}{$\begin{array}{c}\mathrm{r} \\
\text { (до) }\end{array}$} & \multicolumn{2}{c|}{$\begin{array}{c}\mathrm{c} \\
\text { (после) }\end{array}$} \\
\hline & ПВ & ИВ & ПВ & ИВ & ПВ & ИВ \\
\hline М & 3 & 3 & $-0,24$ & $-0,16$ & 0,48 & 0,52 \\
\hline Ц & 2 & 2 & $-0,12$ & 0,14 & 0,70 & 0,84 \\
\hline О & 2 & 2 & 0,09 & 0,13 & 0,76 & 0,82 \\
\hline Дс & 0 & 0 & 0,55 & 0,46 & 0,55 & 0,46 \\
\hline
\end{tabular}

Таблица 8 - Уравнения множественной корреляции между средними месячными значениями параметров ТГМ, Дс, М, Ц, О на ПВ и ИВ после смещения (истинные концентрации)

\begin{tabular}{|c|c|c|c|c|}
\hline Уравнение & $\mathrm{R}^{2}$ & $\mathrm{~F}$ & $\mathrm{~S}$ & $\mathrm{~A}, \%$ \\
\hline ПВ & 0,6 & $\begin{array}{c}13,6 \\
6\end{array}$ & $\begin{array}{c}4, \\
3\end{array}$ & $\begin{array}{c}40,4 \\
5\end{array}$ \\
\hline ТГМ = -12,44 + 9,86 ДСl $+0,98 \mathrm{M}+0,11$ Ц+ 16,98 О & 2 & 6 & \multicolumn{5}{|c|}{} \\
\hline ИВ & 0,6 & 15,8 & 3, & 42,1 \\
\hline
\end{tabular}

Таким образом, моделирование содержания ТГМ в питьевой воде водозаборов поверхностного и инфильтрационного типов по обобщенным 
показателям качества воды водоисточника (мутность, цветность, окисляемость) и дозе хлорирующего агента характеризуется низкими значениями коэффициента детерминации $(0,08$ - 0,30). Использование для моделирования средних месячных значений указанных параметров повышает степень связи и коэффициент детерминации (0,64 и 0,94 для ПВ и ИВ соответственно), позволяет использовать полученные регрессионные уравнения для долгосрочного прогнозирования концентрации ТГМ.

Сопоставление средних месячных значений мутности, цветности, окисляемость, дозы хлора и концентраций ТГМ выявило, что максимум концентраций ТГМ смещен относительно других на 1-3 месяца. Уравнения, в которых учтено смещение показателей качества воды, имеют высокий коэффициент детерминации $(0,86$ и 0,98$)$. Применение такого же смещения для временных рядов истинных концентраций для водозаборов обоих типов позволяет получить уравнения с коэффициентом детерминации 0,62 и 0,65 для ПВ и ИВ соответственно.

\section{Список литературы}

1. Clark R.M., Thurnau R.C., Sivaganesan M., Ringhand P. Predicting the formation of chlorinated and brominated byproducts // Environmental Engineering. 2007. - vol. 127 - P. 493-501.

2. Bull R.G. Health effects of alternative disinfectants and their reaction products. /J. AWWA. - 1980. - vol. 72 - P.214-226.

3. Danileviciute A., Grazuleviciene R., Vencloviene J., Paulauskas A., Nieuwenhuijsen M. J. Exposure to Drinking Water Trihalomethanes and Their Association with Low Birth Weight and Small for Gestational Age in Genetically Susceptible Women // Public Health. - 2012. - 9(12). - P. 4470-4485.

4. Hu J., Song H., Karanfil T. Comparitive analysis of haloniromethane and trihalomethane formation speciation in drinking water: the effects of disifectants, $\mathrm{pH}$, bromide, and nitrite. // Environmental Science Technology. - 2010. - vol. 44 P. 744-749

5. Ivancev-Tumbas I., Dalmacija B., Tamas Z., Karlovic E. The effect of 
different drinking water treatment processes on the rate of chloroform formation in the reactions of natural organic matter with hypochlorite // Water Res. - 1999. - 33, №18. - P. 3715-3722.

6. $\quad$ Lui Y.S., Qiu J.W., Zhang Y.L., Wong M.H., Liang Y. Algal-derived organic matter as precursors of disinfection by-products and mutagens upon chlorination // Water research. - 2011. - vol. 45. - P.1454-1462.

7. Ptoszek Bohdan M. Проблемы очистки воды с высоким содержанием гуминовых веществ // Konf. Politechn. Czest., Czestochowa-Ustron, 4-6 marca, 1998. Czestochowa, 1998. - C. 67.

8. Singer P.C. Control of disinfection byproducts in drinking water // Environmental Engineering. - 1994. - vol. 120 - P. 727.

9. Steve E. Hrudey Chlorination disinfection by-products, public health risk tradeoffs and me // Water research. - 2009. vol. 43. - P. 2057-2092.

10. Wong H., Mok K.M., Fan X.J. Natural organic matter and formation of trihalomethanes in two water treatment processes //Desalination. - 2007. - vol.210. P.44-51.

11. Васильева А.И. Влияние хлорирования на качество воды в присутствии некоторых природных и техногенных примесей: Дисс. к.х.н. - Уфа, 2008. 202 c.

12. Детин И.И., Мельцер В.В., Медриш Г.Л. Очистка и обеззараживание природных вод для питьевых целей // Экология и приборостроение. - 1991. C. 15-19.

13. Иванов А.В., Тафеева Е.А., Давлетова Н.Х., Вавашкин К.В.Современные представления о влиянии качества питьевой воды на состояние здоровья населения // Вода: химия и экология. - 2012. - № 3. - С. 48-53.

14. Кантор Л.И., Харабрин С.В. Выявление особенностей изменения концентрации бромсодержащих тригалогенметанов в питьевой воде двух инфильтрационных и поверхностного водозаборов // Вода и экология. - 2004. № 1. - С. 7-9.

15. Кобзарь А.И. Прикладная математическая статистика. Для инженеров и 
научных работников. - М.:ФИЗМАТЛИТ, 2006 - 816 с.

16. Красовский Г.Н., Егорова Н.А., Букшук А.А. Гигиеническая оценка продуктов хлорирования питьевой воды с учетом множественности путей поступления в организм // Гигиена и санитария. - 2013. Т.92(№ 2). - С. 18-24.

17. Малкова М.А., Кантор Е.А., Вождаева М.Ю. Прогнозирование концентрации тригалогенметанов в питьевой воде // Успехи современного естествознания. 2018. № 4. С. 133-138.

18. Малкова М.А. Мониторинг хлорирования воды хозяйственно-питьевого назначения и поиск путей снижения содержания галогенорганических соединений в питьевой воде: Автореф. дис. ... канд. хим. наук: 03.02.08; [Место защиты: РГУ нефти и газа им. Губкина]. — Уфа, 2019. — 24 с.

19. Муллина Э.Р. Химические аспекты процесса хлорирования воды // Международный журнал прикладных и фундаментальных исследований. 2016. - T.4 - № 12 - С. 609-613.

20. Соколова Н. Ф., Истомина Т. И. Эффективность различных хлорактивных соединений при обеззараживании воды, содержащей бактерии и вирусы. Проблемы дезинфекции и стерилизации. Сб. науч. трудов ВНИИДиС. - 1976. -Вып.2 - С.64-67.

21. Х Харабрин А.В., Харабрин С.В., Кантор Л.И., Кантор Е.А., Клявлин М.С. Об изменении мутности, цветности, перманганатной окисляемости и $\mathrm{pH}$ воды реки Уфа // Башкирский химический журнал. - 2003. - Т. 10. - № 3 - С. 80-81.

22. Харабрин С.В., Кантор Е.А., Кантор Л.И.. Влияния типа водозабора на сезонные изменения концентрации бромсодержащих тригалогенметанов // Сборник тезисов VIII Международной научно-технической конференции при VIII Международной специализированной выставке «Строительство. Коммунальное хозяйство. Энергосбережение - 2004». - Уфа: Изд-во УГНТУ. T. 1. - 2004. - C. 180 - 181.

23. Шевченко М.А., Таран П.Н. Возможности использования хлора для очистки природных и сточных вод// Химия и технология воды. - 1984. - Т.6, №6. - С. 537-546. 
24. Эконометрика / И.И. Елисеева, Курышева С.В., Костеева Т.В. и др. /М.: Статистика и финансы, 2001. - 344 с.

* Работа выполнена в рамках государственного задания Минобрнауки России в сфере научной деятельности, номер для публикаций FEUR - 2020 0004 «Решение актуальных задач и исследование процессов в нефтехимических производствах, сопровождающихся течениями многофазных сред» 